Firstly, the patient's medical and occupational history must be carefully reviewed, asking specifically about materials handled at work. Ask about a patient's work rather than his "job," for most of us warm to this approach, and people are pleased to explain what they do, what it entails, and what they handle. 'After all, "labourers" do not just dig holes in the road or carry bricks up ladders. They may work in diverse places such as a chemical factory, a foundry, or a cotton mill, while a "stoker" may well spend all day in a white coat seated in front of a control panel. Surprisingly, the construction industry (often recorded as "building" in medical notes) includes demolition, such as cutting through painted steel, which is how building workers get lead poisoning.

Secondly, when the substance produces an acute effect direct questions should show the relation between symptoms and work; one useful line is evidence of remissions at weekends and holiday periods. The clinical effects of exposure to toxic material may not appear until a few hours after exposure. Patients may wake up breathless at night from something they have handled during the day. Occupational asthma is a good example of a disorder in which both "immediate" and "non-immediate" effects may occur. ${ }^{2}$ Sensitisation, usually of the skin or respiratory tract, may appear soon after starting work with a new substance, or it may appear only after several years of work with the substance concerned. Long term effects, such as occupational cancers, may take 20 years or more to develop and thus the link with previous industrial exposure may be harder to substantiate, especially if the employee has left the suspect job some years before.

Thirdly, a frequently forgotten but most useful question is whether fellow workers have similar symptoms or illnesses, remembering that colleagues at work share infections as well as exposure to environmental hazards.

Once the doctor suspects an occupational cause for disease identifying the precise cause may be difficult because the patient may know only the name of an apparently obscure chemical or, worse still, a meaningless trade name. This, however, is becoming less of a problem than it was because it is now well recognised that workers should not be exposed to substances which they or their employer know nothing about. Employees need to have information and instructions about the substances they handle for they cannot reasonably be expected to cooperate with preventive measures unless they are well informed. ${ }^{3}$ The Health and Safety at Work Act requires employers to provide adequate information and training in such matters, ${ }^{34}$ and patients often now arrive at the surgery carrying specially prepared leaflets.

If the employer does not know about the harmful effects (or the absence of harmful effects) of a substance the same Act obliges manufacturers, suppliers, and others to provide adequate information about any measures that are necessary to protect the health and safety of the user. ${ }^{45}$ Furthermore, when such information is not available the manufacturer or supplier may be obliged to undertake research to eliminate or minimise any risks to health and safety.

If the doctor feels disinclined to pursue the matter directly with the employer he may contact the occupational physician (if there is one) or a medical colleague in the Employment Medical Advisory Service, to be found under "Health and Safety Executive" in the telephone directory. Unfortunately, this may not yield the desired information because the Health and Safety at Work Act (section 28) restricts the freedom of employment medical advisers to pass information on to other doctors, though it seems they may pass it on to officers of local authorities, water authorities, or police constables. ${ }^{6}$ Nevertheless, despite these restrictions employment medical advisers are generally extremely helpful. Perhaps things will be easier if new regulations, now in draft form, become law. ${ }^{7}$

Professor of Occupational Health,
University of Manchester,

W R LEE

Manchester M13 9PT

1 Finkel AJ. Hamilton and Hardy's industrial toxicology. 4th ed. London: John Wright, 1983:1-2.

2 Morgan WKC, Seaton A. Occupational lung diseases. 2nd ed. Philadelphia: W B Saunders Company, 1984:502.

3 Drake CD, Wright FB. Law of health and safery at work. London: Sweet and Maxwell, 1983:78,92. Health and Safery at Work Act 1974. London: HMSO, 1974. (Section 2(2)(c).)

Health and Safety at Work Act 1974. London: HMSO, 1974. (Section 6 .

6 Health and Safery at Work Act 1974. London: HMSO, 1974. (Section 28.)

Health and Safety Commission. Control of substances hazardous to health. Consultative document. Draft regulations and draft approved code of practice. London: HMSO, 1984.

\section{Psychogenic cough in childhood}

All those concerned with the care of children and adolescents will be familiar with the young patient who seems relatively well apart from a persistent cough. The child is usually not particularly worried about the symptom-unlike his parents, teachers, and friends, who find it intensely irritating. The cough may be a sufficient social nuisance to prevent the child attending school for weeks or even months at a time. Sometimes the general practitioner will work systematically through the Mims list of cough suppressants, expectorants, and antibiotics with little, if any, improvement. Many of the children will eventually be referred to a paediatric or chest clinic, where he or she will often have to submit to numerous investigations-all the results of which eventually prove negative.

The condition these children have is variously called psychogenic cough, psychogenic cough tic, ${ }^{1}$ or honking. ${ }^{2}$ The diagnostic features which should alert the clinician include total absence of cough during sleep, often a harsh, explosive barking quality to the cough said to be reminiscent of the Canadian goose-hence the term "honker,"' and the ability of the affected child to produce the cough on request. Most honkers are between 6 and 14 years. Characteristically the symptoms start at a time when the child has an upper respiratory tract infection. Some appear to be under psychological stress, including school phobias and parental strife, ${ }^{3}$ and in a recent publication most were claimed to have either absent or depressed gag and corneal reflexes, features which are often associated with symptoms of conversion hysteria. ${ }^{4}$

Clearly organic causes must be excluded before the clinician makes a diagnosis of psychogenic cough. Asthma can present with recurrent cough with little or no wheezing or breathlessness, particularly in the younger child. ${ }^{5}$ Other causes include whooping cough, an aspirated foreign body, bronchiectasis, and cystic fibrosis. Whether or not a postnasal drip secondary to upper respiratory tract infection can itself produce persistent coughing is doubtful ${ }^{6}$-it may simply reflect the coexistence of pathological processes in the upper and lower respiratory tract. ${ }^{7}$ An older child should certainly be gently questioned about smoking. Clinically all that is normally needed is a careful history and examination, peak flow measticements before and after $\beta_{2}$ adrenergic stimulants, and chest radiographs (with views in inspiration 
and expiration if a foreign body is suspected), but at times additional, more invasive tests may be indicated.

The long term outcome is almost always excellent for the child with a psychogenic cough, but as the symptoms may persist for months - or even years-an early remission will benefit both the child's education and the family's sanity. Usually the cough will resolve after the parents are reassured that there is no underlying disease and that it is simply a habit or tic. If reassurance fails or if there are other obvious behavioural problems psychiatric referral may be helpful. ${ }^{3} \mathrm{~A}$ recent publication from New York has suggested a more dramatic and apparently highly effective approach which the authors describe as a reinforced suggestion technique. ${ }^{4}$ Once the diagnosis has been made the patient is informed that his cough has weakened his chest and that as a result he needs a chest support. This is provided by tying a folded bed sheet around the child's chest, leaving a large knot over his sternum. Any attempt to cough after tightening the knot leads to sharp commands to "stop coughing." In 31 out of 33 patients this proved effective within 24 to 48 hours with no subsequent relapse. This rather colourful approach may not appeal to all. There is little doubt, however, that this condition is grossly underdiagnosed and that a happy outcome may almost always be achieved once the parents understand the nature of the condition.

A D MiLNER

Professor of Paediatric Respiratory Medicine,

University Hospital,

Nottingham NG7 2UH

1 Korach A. Psychogenic cough tic in children and adolescents: nine case histories illustrate the need for re-evaluation of this common but frequently underdiagnosed problem. Clin Pediatr (Phila) $1969 ; 8: 580-3$.

2 Weinberg EG. "Honking," psychogenic cough tic in children. S Afr Med $\mathcal{f}$ 1980;57:198-200.

3 Shuper A, Mukamel M, Mimount M, Lerman M, Varsono I. Psychogenic cough. Arch Dis Child 1983;58:745-7.

4 Cohlan S, Stone SM. The cough and the bed sheet. Pediatrics 1984;74:11-5.

5 Konig P. Hidden asthma in childhood. Am $\mathcal{f}$ Dis Child 1981;135:1053-5.

6 Irwin RS, Pratter MR, Holland PS, Corvin RW, Hughes JP. Post-nasal drip causes cough and is associated with reversible upper airways obstruction. Chest 1984;85:346-51.

7 Phelan P. Post-nasal drip and chronic cough. Lancet 1978;ii: 1309.

\section{The Education Act 1981}

The Education Act 1981, which became law on 1 April 1983, has tried to provide adequate safeguards, rights, and duties for all those concerned with the education of children with special educational needs and to ensure these children's right to be integrated into the life and work of the community. ${ }^{1}$ It also gives effect to the recommendations of the Warnock report, which emphasised the importance of early identification of children with special educational needs and, where possible, provision for their education in normal schools. ${ }^{2}$ Although many doctors may be unaware of the statutory obligations of the Act, there can be few for whom it will not at some stage have implications.

Among other things the Act requires that if a child is identified by a doctor employed by a health authority as having, or being likely to have, a special educational need then certain steps must be taken. Firstly, the parents must be informed and the matter discussed with them. Secondly, the parents should be put in touch with any voluntary organisation that is likely to be able to give them advice or help. Thirdly, if the child is aged under 2 years the parents must be asked if they would like the education authorities to be informed that their child has (or may have) special educational needs. If the child is over 2 they need to be advised that the health authority has a statutory obligation to inform the education authority. Finally, the education authorities must then be informed about the child.

Sadly, but not surprisingly, the Act contains no clear definition of what "special educational needs" means except for the tautological and medically unhelpful statement that "a child has special educational needs if he has a learning difficulty which calls for special educational provision to be made for him." The term clearly includes the $2 \%$ of children who have severe handicaps-for example, most children with cerebral palsy, muscular dystrophy and other disabling muscular disorders, spina bifida, severe mental retardation, severe psychiatric disturbances, severe visual and auditory disturbances, orthopaedic conditions that prevent the child walking normally, severe inoperable congenital heart disease, and severe speech defects. Whether, however, it includes a further $18 \%$ or so of children with less severe forms of handicap such as an intelligence quotient between 50 and 70 , reading retardation 28 months behind the norm for that age, moderately severe behaviour disorders, and illness of more than a year's standing such as asthma or epilepsy is not clear. At present individual education authorities may choose for themselves how many of these children they will regard as falling within the terms of the Act.

Once the education authorities have been informed by the health authorities about a child they must decide what further assessments-medical, psychological, and educational-should be made and whether a formal statement is needed with respect to the child's future education. Parents may themselves request an assessment of their child and, indeed, may participate fully at all stages of the procedure. They have access to the medical assessment that is passed to the education authorities and if they do not agree with the final statement from the education authorities they have the right of appeal.

In practice, each district has a medical officer who is responsible for liaising with the educational authorities and through whom most communications concerning the Act are channelled. If the education authority decides that it needs a medical assessment on a particular child it should inform the designated medical officer and they may choose to delegate the task of assessment to a doctor who has been directly concerned with the child's welfare-for example, the school doctor, a paediatrician, or a doctor in charge of an assessment centre. The doctor making the assessment has to collect information from all those who look after the child including workers in the paramedical support services. The assessment is, therefore, based on reports from such diverse sources as general practitioners, orthopaedic, ear, nose, and throat, and ophthalmic specialists, physiotherapists, occupational therapists, and health visitors. The report for the education authority should state exactly what treatment the child needs, for even if the health authority is unable to provide it the parents should know that the child has been identified as having a need which cannot be met. They may then appeal and give the professionals concerned the opportunity to apply further pressure on the health authority.

Problems have arisen already since the Act came into effect. In a recent survey, covering $78 \%$ of districts, nearly half the designated officers were not of consultant status, and in two thirds of the districts which replied, implementation of the Act had resulted in a measurable increase in demand for resources (report of the Association of District Medical Officers). Nevertheless, no extra funds have been provided to either the health or the education authorities for implementing the Act. 